\title{
The Effect of Welding-Pass Grouping on the Prediction Accuracy of Residual Stress in Multipass Butt Welding
}

\author{
Jeongung Park, ${ }^{1}$ Gyubaek An, ${ }^{2}$ and Sunghoon Kim $^{3}$ \\ ${ }^{1}$ Department of Civil Engineering, Chosun University, Gwangju, Republic of Korea \\ ${ }^{2}$ Department of Naval Architecture and Ocean Engineering, Chosun University, Gwangju, Republic of Korea \\ ${ }^{3}$ Department of Automotive Mechanical Engineering, Nambu University, Gwangju, Republic of Korea \\ Correspondence should be addressed to Gyubaek An; gyubaekan@chosun.ac.kr
}

Received 1 September 2016; Revised 24 November 2016; Accepted 28 December 2016; Published 30 January 2017

Academic Editor: Bernard Bonello

Copyright (C) 2017 Jeongung Park et al. This is an open access article distributed under the Creative Commons Attribution License, which permits unrestricted use, distribution, and reproduction in any medium, provided the original work is properly cited.

\begin{abstract}
The residual stress analysis of a thick welded structure requires a lot of time and computer memory, which are different from those in thin welded structure analysis. This study investigated the effect of residual stress due to welding-pass grouping as a way to reduce the analysis time in multipass thick butt welding joint. For this purpose, the parametric analysis which changes the number of grouping passes was conducted in the multipass butt weld of a structure with a thickness of $25 \mathrm{~mm}$ and $70 \mathrm{~mm}$. In addition, the residual stress by thermal elastoplastic FE analysis is compared with the results by the neutron diffraction method for verifying the reliability of the FE analysis. The welding sequence is considered in order to predict the residual stress more accurately when using welding-pass grouping method. The results of the welding-pass grouping model and half model occurred between the results of the left/right of the full model. If the total number of welding-pass grouping is less than half of that of welding pass, a large difference with real residual stress is found. Therefore, the total number of the welding-pass grouping should not be reduced to more than half.
\end{abstract}

\section{Introduction}

The safety of the steel structure poses an issue as the thickness of a component is increased following the large size of a structure which is intended to maximize productivity and efficiency. With the increases of ships and plant structures operating under a low-temperature environment, the brittle fracture safety of the structure becomes an important issue. An et al. $[1,2]$ performed a large-scale brittle fracture test for various thicknesses in order to find out the factors affecting unstable fracture by applying high-heat input welding process and low-heat input welding process. In addition, they investigated the effect of residual stress on the unstable fracture by measuring residual stress distribution $[3,4]$ according to each welding process. They found out that crack propagation path, which was generated during unstable fracture, was largely affected by the residual stress according to welding process. The residual stress distribution towards thickness particularly affected the crack propagation path greatly. Therefore, the measurement and predication of the welding residual stress are highly important in order to evaluate structure safety. In order to evaluate the generation and propagation of a crack, it is important to measure not only surface residual stress but also internal residual stress. Surface residual stress can be measured by X-ray method [5], hole drilling method [6], and so forth while internal residual stress can be measured by neutrons $[7,8]$, deep-hole drilling $[9,10]$, inherent strain $[3$, 11], and contour method [12]. In this study, neutron method was used to measure internal residual stress in order to compare with the result of thermal elastoplastic FE analysis.

There are broadly two methods to predict welding residual stress in a large steel structure: thermal elastoplastic analysis and inherent strain method. Thermal elastoplastic analysis $[13,14]$ is a method of performing heat distribution and thermal elastoplastic stress analysis to predict welding deformation and residual stress that occur along with the 


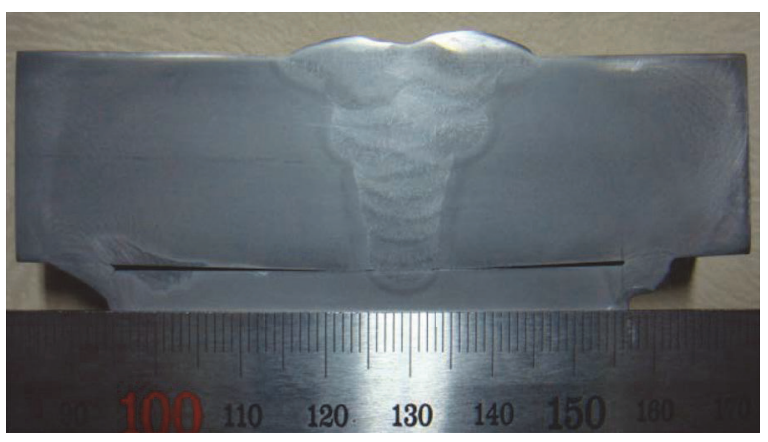

(a) Thickness $=25 \mathrm{~mm}$

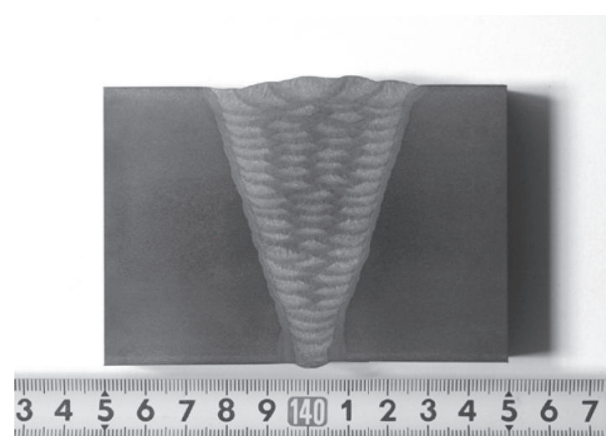

(b) Thickness $=70 \mathrm{~mm}$

Figure 1: Cross-sectional macrostructure of (a) $25 \mathrm{~mm}$ and (b) $70 \mathrm{~mm}$.

TABLE 1: Properties of base metal.

\begin{tabular}{lccccc}
\hline Thickness $(\mathrm{mm})$ & Material & Remark & YP $(\mathrm{MPa})$ & TS $(\mathrm{MPa})$ & EL $(\%)$ \\
\hline $25 \mathrm{~mm}$ & EH47-grade & Steel & 490 & 590 & 21 \\
70 & EH40-grade & Steel & 390 & 530 & 21 \\
\hline Consumables & & & 570 & 610 & 19 \\
\hline
\end{tabular}

movement of the welding heat source. With this method, even for the case of a coupon-size specimen, a huge amount of time for modeling and analysis is consumed [15]. If the analysis subject is large, the analysis may not be possible due to the excessive time consumed and shortage of memory capacity of the computer. Recently, a study method to analyze welding residual stress has progressed by accelerated explicit method. Accelerated explicit method [16] and idealized explicit FEM [17] drastically reduced the memory usage so that large-scale models for residual stress and welding deformation can be analyzed. To reduce the analyzing time, the GPU parallel computing [17-19] was adopted and the welding distortions in large models of a construction structure and a suspension unit in automotive structures [19] were computed with a high efficiency. A welding residual stress prediction method by elasticity analysis was studied in order to resolve the issue of calculation time and the capacity of computer for thermal elastoplastic analysis. The representative method is the inherent strain method $[3,11]$. This method predicts residual stress and deformation by using inherent strain, which is the source of residual stress and deformation. For that, the database of inherent strain distribution from thermal elastoplastic analysis or many experiment results are needed.

As previously described, measuring and predicting residual stress, according to the increase of thickness of steel structures, are important. Total welding pass in butt welding joint is about 60 passes in case of a thickness of $60 \mathrm{~mm}$. The residual stress analysis of thick welded structure requires a lot of time and computer memory and should not be compared to those in thin welded structure analysis. Recently, weld pass grouping method $[20,21]$, which merges several welding passes during welding FE analysis, has been applied in order to compensate for these problems although it can induce some unsatisfying results in welding deformation. The results of FE analysis using welding-pass grouping agree well in thin welding joint. However, in thick welded joint, which has an $\mathrm{X}$-shaped groove with 23 layers and 108 welding passes, the thermal elastoplastic analysis needs a lot of analysis time even if the GPU parallel computing is employed. Thus, in order to reduce analysis time and memory, a total of 23 layers were reduced by 6 layers (26\%). The welding residual stress of the full model and grouping model [22] has a lot of differences, however. There is a lack of research on welding-pass grouping because the existing research has been studied in thin welding joint and specific conditions.

This study investigated the effect of residual stress due to welding-pass grouping as one way to reduce the analysis time in multipass thick butt welding joint. For this purpose, the parametric analysis which changes the number of grouping passes was conducted in the multipass butt weld of a thickness of $25 \mathrm{~mm}$ and $70 \mathrm{~mm}$. In addition, the residual stress by thermal elastoplastic FE analysis is compared with the results by the neutron diffraction method for verifying the reliability of the FE analysis.

\section{Experiment and Measurement of Residual Stress Using the Neutron Diffraction Method}

The specimens used in this research have a thickness of $25 \mathrm{~mm}$ and $70 \mathrm{~mm}$ and multipass butt welding joint. The specimen with a thickness of $25 \mathrm{~mm}$ had a width of $280 \mathrm{~mm}$ and length of $100 \mathrm{~mm}$, while the specimen had a thickness of $70 \mathrm{~mm}$, width of $400 \mathrm{~mm}$, and length of $200 \mathrm{~mm}$. The physical properties of two steel materials and welding wires are shown in Table 1. FCAW welding was applied for both materials having two types of thicknesses, and the detail of the welding condition is tabulated in Table 2. Figure 1 shows a micro crosssection of steel plates having a thickness of 25 and $70 \mathrm{~mm}$. 
TABLE 2: Welding condition.

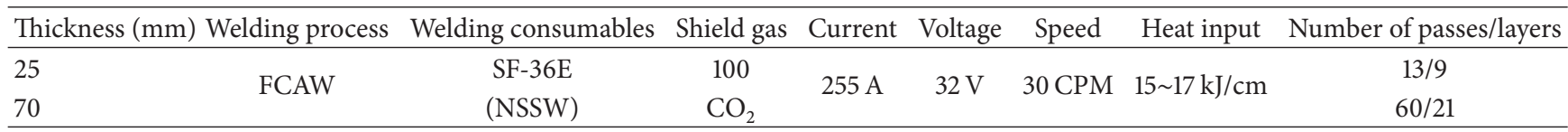

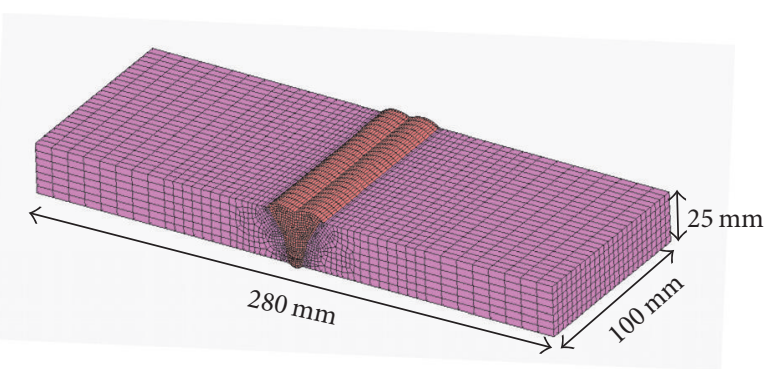

(a) Full and full grouping model

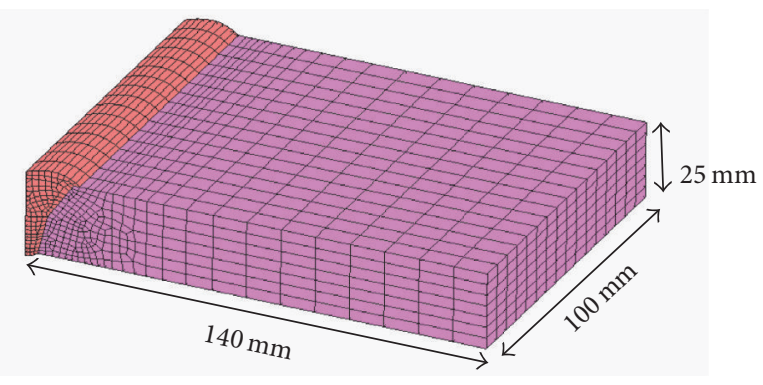

(b) Half model

FIGURE 2: Dimension of model of thickness $25 \mathrm{~mm}$.

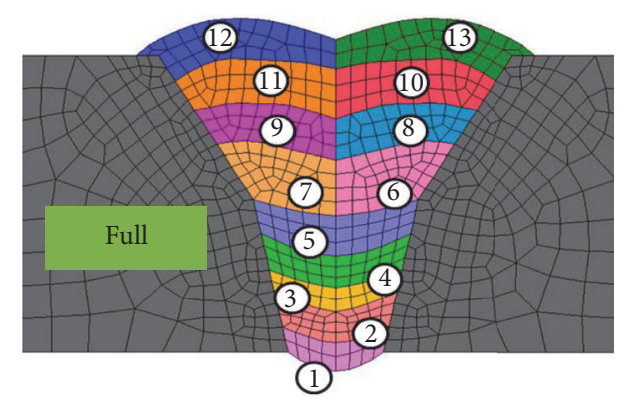

(a) Full model

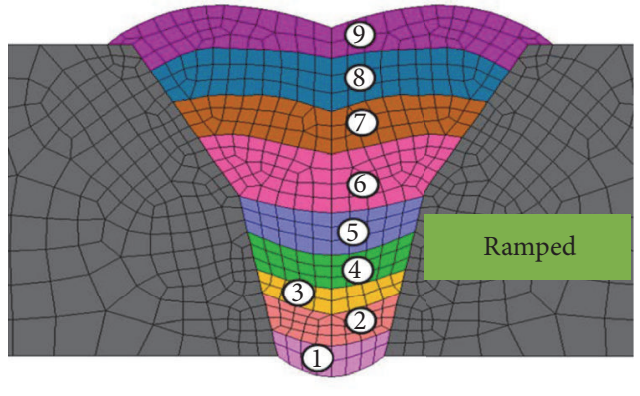

(b) Full grouping model

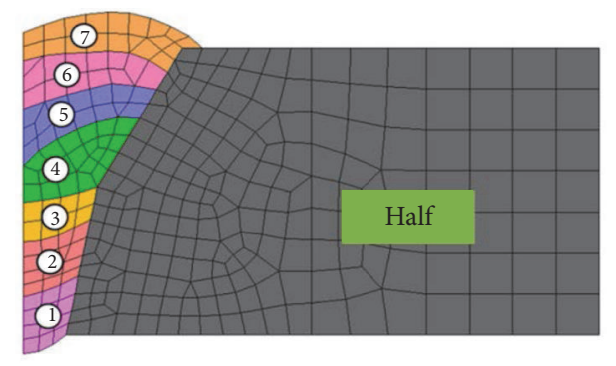

(c) Half model

FIGURE 3: Welding sequences of thickness $25 \mathrm{~mm}$.

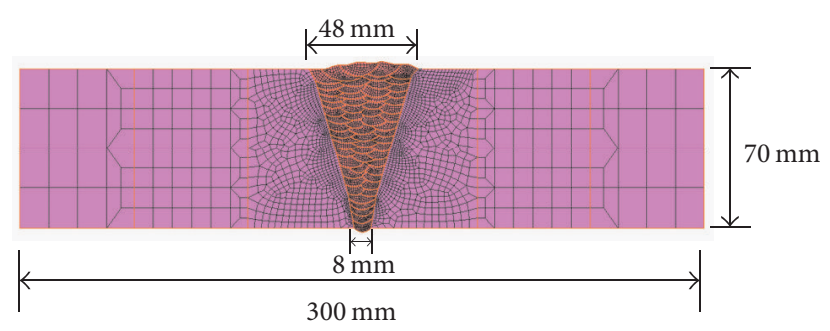

Figure 4: Dimension of model of thickness $70 \mathrm{~mm}$. 


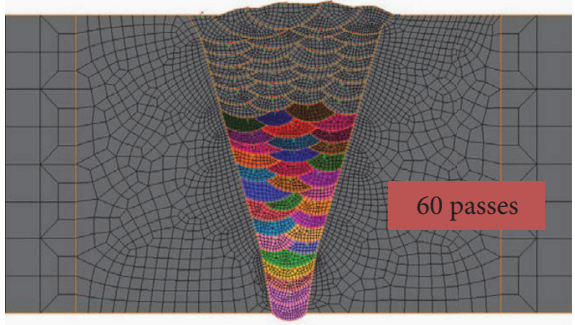

(a) 60 passes

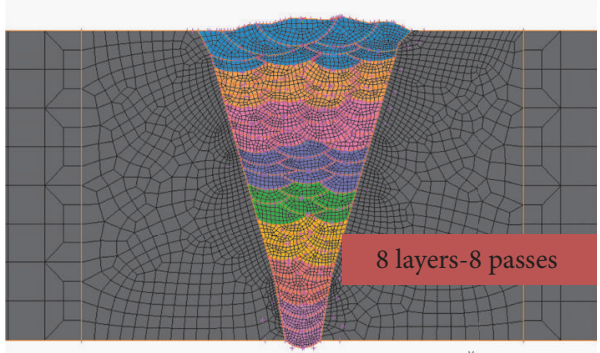

(c) 8 layers- 8 passes

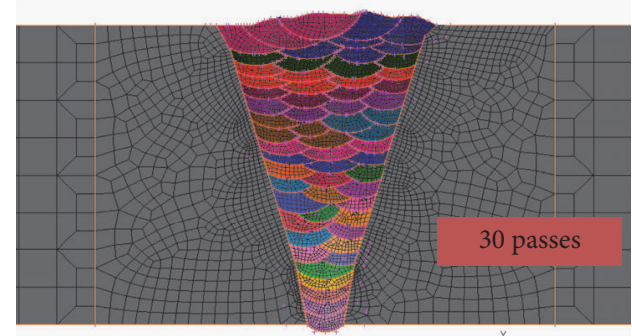

(b) 30 passes

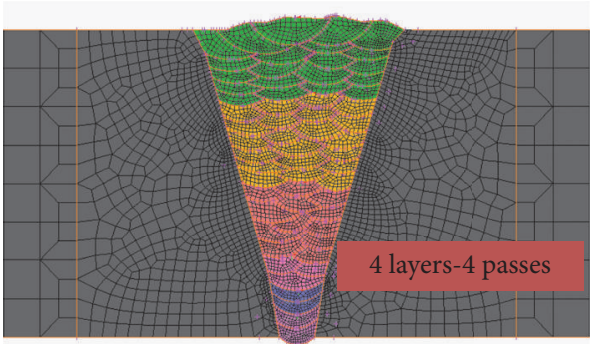

(d) 4 layers-4 passes

FIGURE 5: Welding sequences of thickness $70 \mathrm{~mm}$.

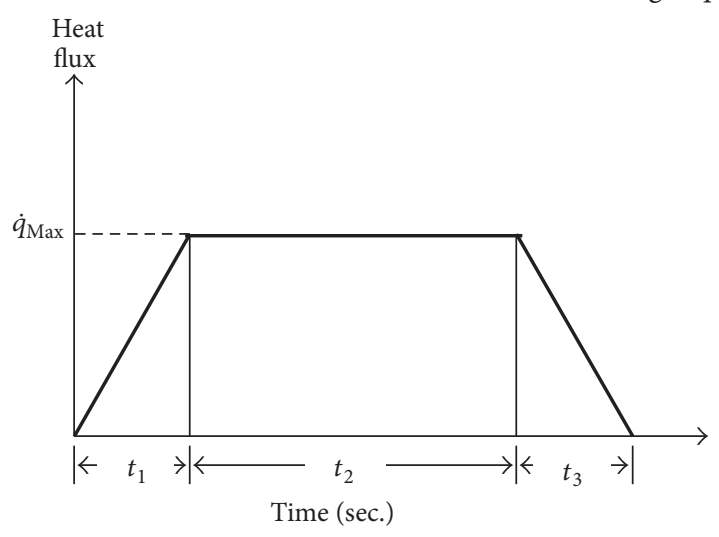

(a) Ramped heat input function

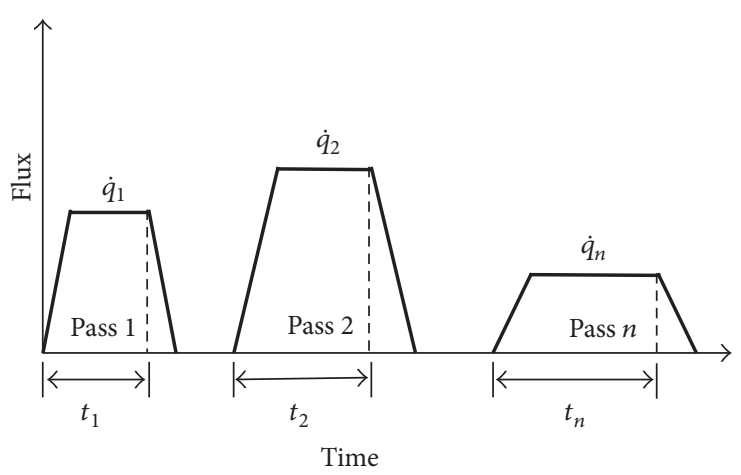

(b) Ramp functions of welding passes before lumping

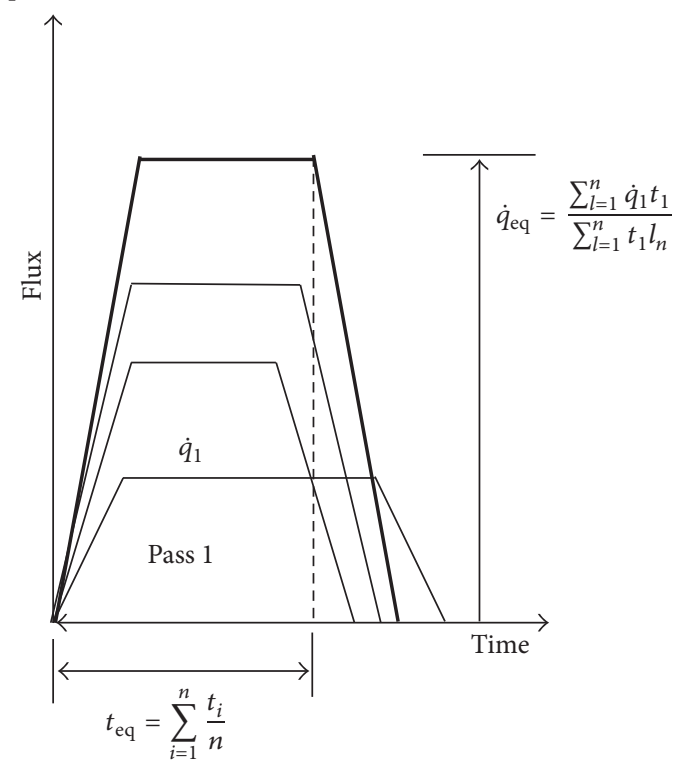

(c) Ramp function after lumping

FIgURE 6: Grouped weld passes model. 


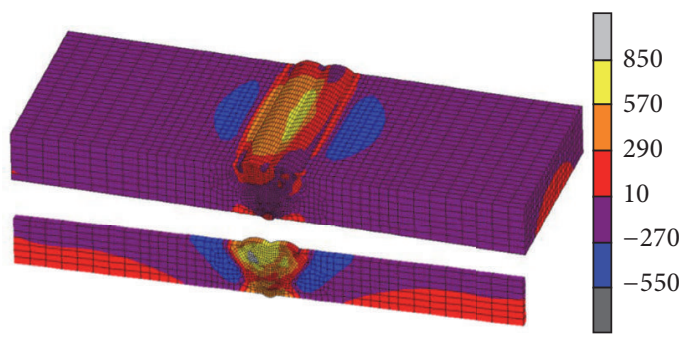

(a) Full model

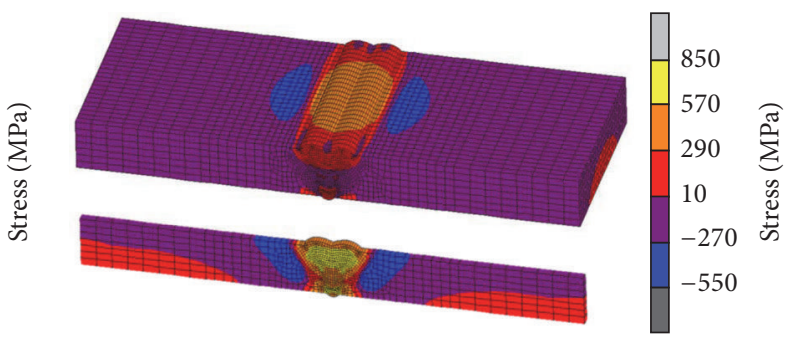

(b) Full grouping model

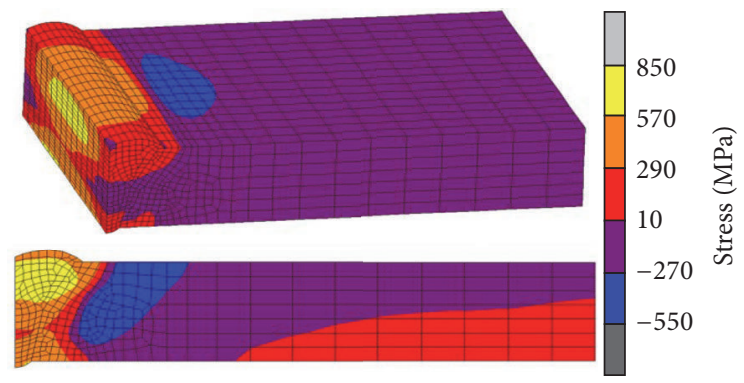

(c) Half model

Figure 7: Welding residual stress of thickness $25 \mathrm{~mm}$.

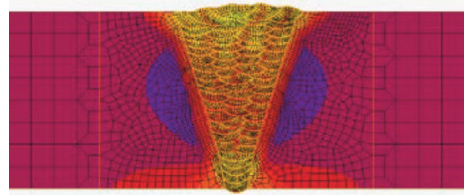

$\sigma_{x}$

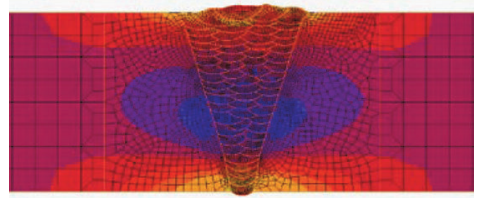

$\sigma_{y}$

(a) 60 passes
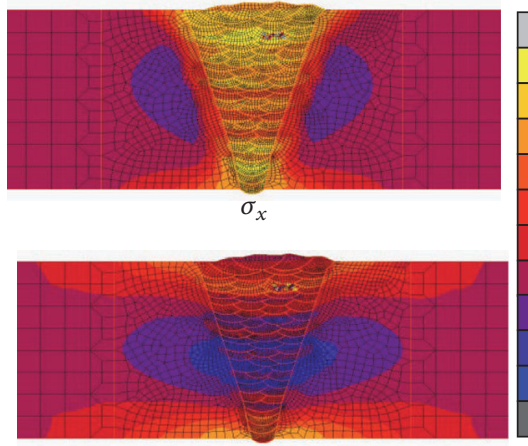

$\sigma_{y}$

(c) 8 layers- 8 passes

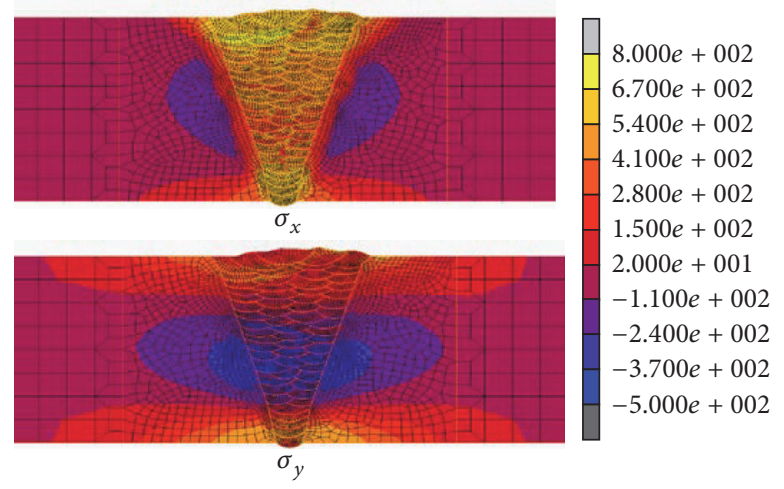

(b) 30 passes

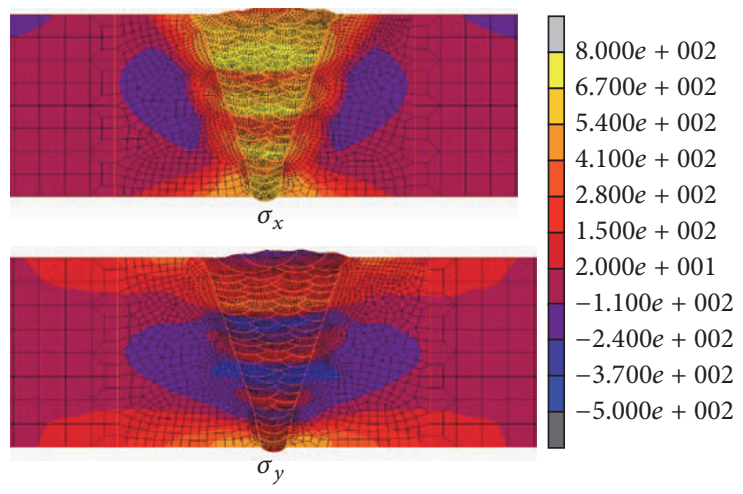

(d) 4 layers-4 passes

FIGURE 8: Welding residual stress of thickness $70 \mathrm{~mm}$. 


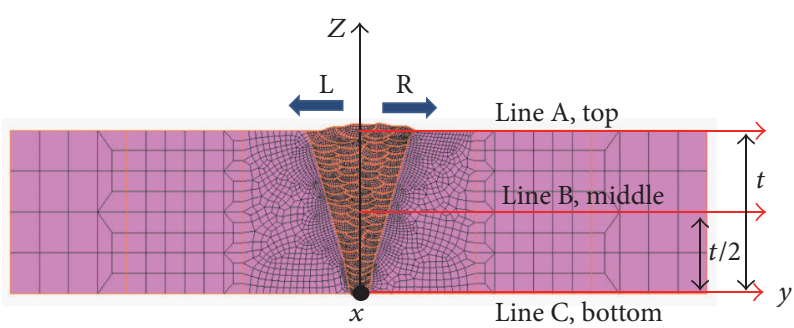

FIgURE 9: Measurement and comparison position.

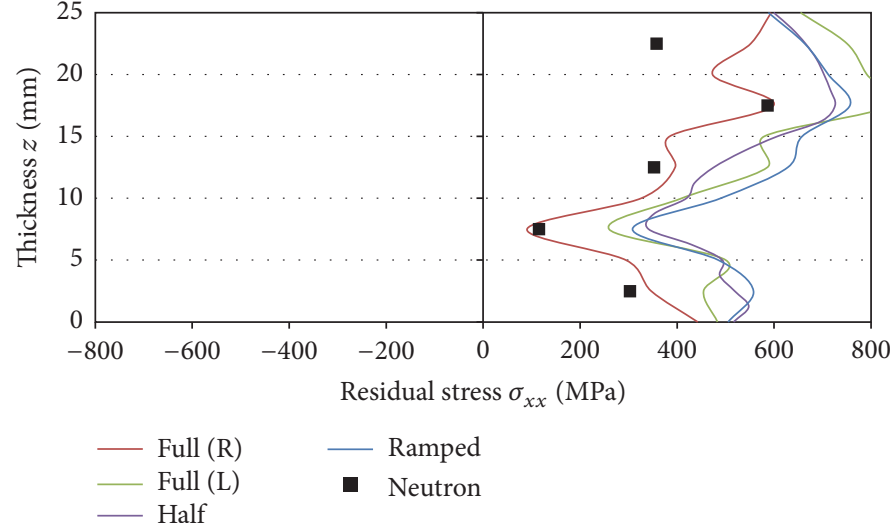

(a)

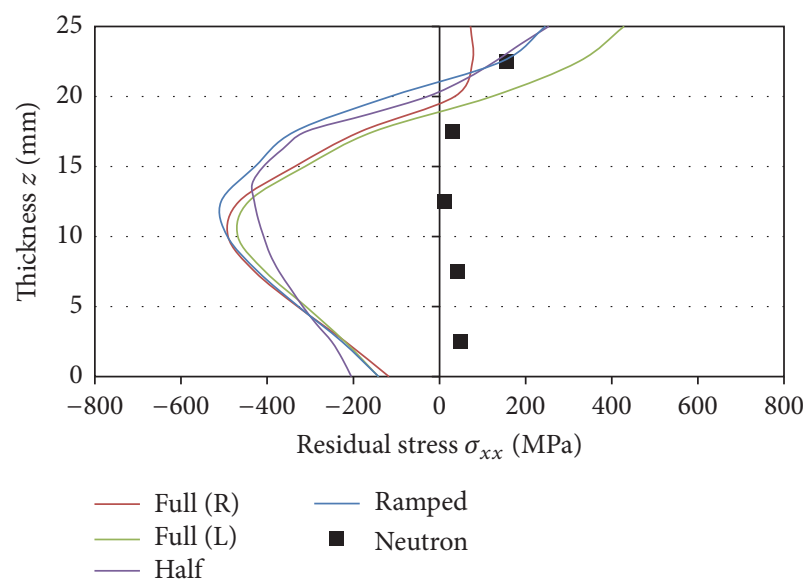

(c)

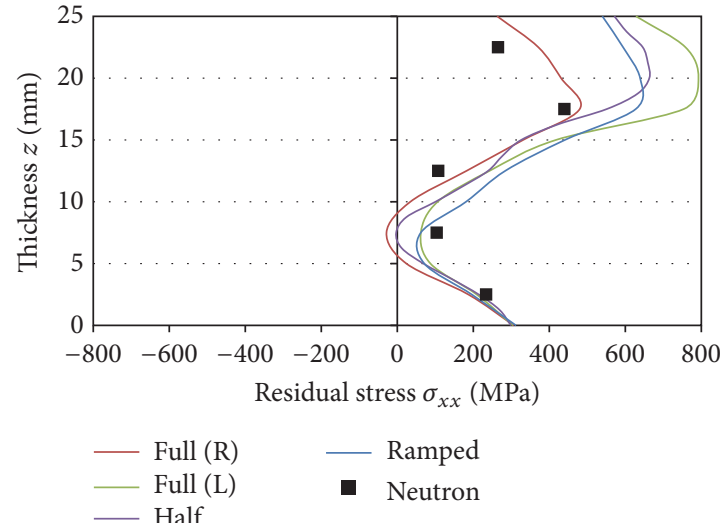

(b)

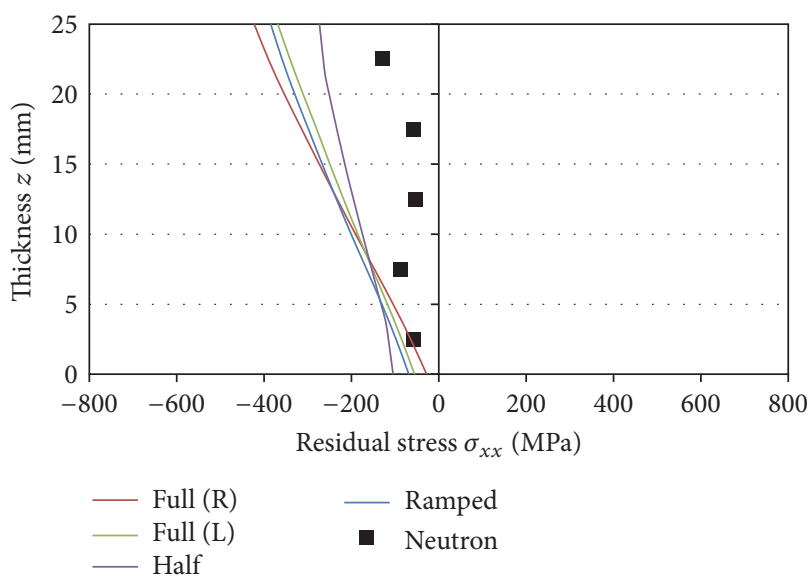

(d)

Figure 10: Welding residual stress in welding direction, thickness $=25 \mathrm{~mm}$ at (a) $y=5 \mathrm{~mm}$, (b) $y=12.5 \mathrm{~mm}$, (c) $y=20 \mathrm{~mm}$, and (d) $y=35 \mathrm{~mm}$.

The material having a thickness of $25 \mathrm{~mm}$ has 9 layers and 13 passes, while the material having a thickness of $70 \mathrm{~mm}$ has 21 layers and 60 passes.

Welding residual stress was measured by neutron diffraction method using the same specimens of the experiment. The residual stress is measured by neutron diffraction method using the change of the interplanar distance of the lattice plane when elastic stress loads on each grain constituting the material. Neutron beam scatters in various directions due to atom but neutron beam can be expressed by Bragg's law under atom regularly arranged in three dimensions as follows.

$$
2 d \sin \theta=n \lambda \text {. }
$$

Here, $d$ is the interplanar distance of the lattice plane, $\theta$ is the diffraction angle, and $\lambda$ is the wave length of the neutron.

$$
\varepsilon=\frac{\Delta d}{d_{0}}=\frac{d_{0}-d}{d_{0}}=-\cot \theta_{0} * \Delta \theta
$$




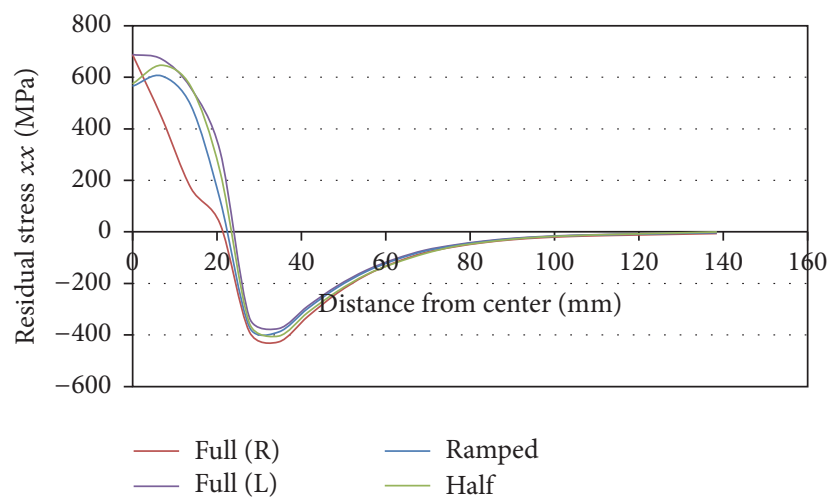

(a) At line top, $z=25 \mathrm{~mm}$

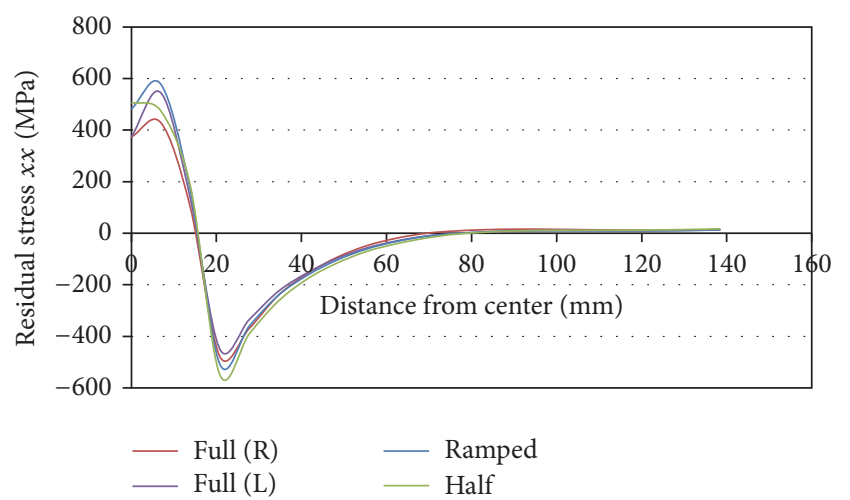

(b) At line middle, $z=12.5 \mathrm{~mm}$

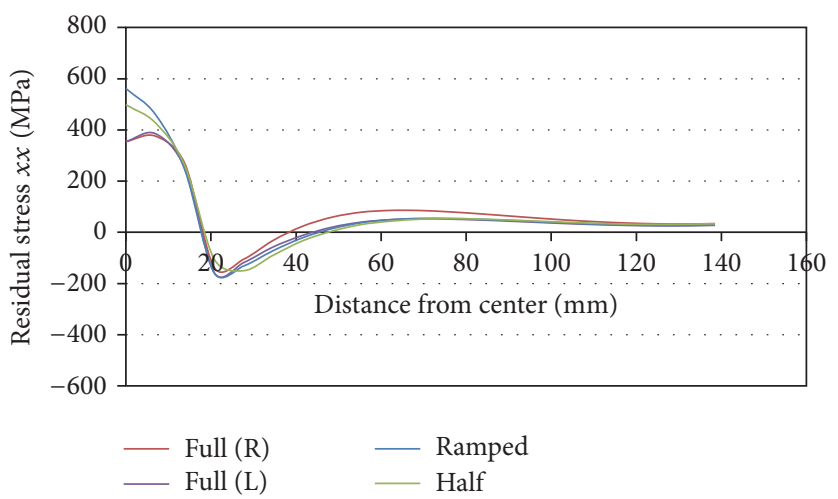

(c) At line bottom, $z=0 \mathrm{~mm}$

FIGURE 11: Welding residual stress in welding direction, thickness $=25 \mathrm{~mm}$ at line top (a), middle (b), and bottom (c).

Here, $\Delta d$ is the difference of the interplanar distance of the lattice plane $\left(d_{0}-d\right), d_{0}$ is the initial interplanar distance of the lattice plane without stress, $\Delta \theta$ is the difference of diffraction angle, and $\theta_{0}$ is the initial diffraction angle without stress.

Diffraction angle is changed according to changing the interplanar distance of the lattice plane due to residual stress or load stress. Rewritten by differentiating (1), strain $(\varepsilon)$ is equal to the following expression. Strain $(\varepsilon)$ can be calculated by measuring the difference of the interplanar distance of the lattice plane or diffraction angle. Therefore, when we measure the residual stress using neutron diffraction method, we should measure the initial diffraction angle $\left(\theta_{0}\right)$ after stress relief heat treatment. Residual stresses $\left(\sigma_{x}, \sigma_{y}, \sigma_{z}\right)$ can be obtained with three-direction strains $\left(\varepsilon_{x}, \varepsilon_{y}, \varepsilon_{z}\right)$ and Young's modulus (E) using (3). In this study the residual stress was measured by neutron diffraction method to verify the authenticity of the analysis result and was compared using comparative analysis.

$$
\begin{aligned}
& \sigma_{x}=\frac{E}{1+v}\left[\varepsilon_{x}+\frac{v}{1-2 v}\left(\varepsilon_{x}+\varepsilon_{y}+\varepsilon_{z}\right)\right], \\
& \sigma_{y}=\frac{E}{1+v}\left[\varepsilon_{y}+\frac{v}{1-2 v}\left(\varepsilon_{x}+\varepsilon_{y}+\varepsilon_{z}\right)\right], \\
& \sigma_{z}=\frac{E}{1+v}\left[\varepsilon_{o}+\frac{v}{1-2 v}\left(\varepsilon_{x}+\varepsilon_{y}+\varepsilon_{z}\right)\right] .
\end{aligned}
$$

\section{Modeling and Grouping of Multipass Welding Sequence}

Figure 2 shows the dimensions of the full model, full pass grouping model, and half model of the multipass butt joint specimens with a thickness of $25 \mathrm{~mm}$ used in this FE analysis and experiment. The three-dimensional solid element and moving heating source were used in the FE analysis. The temperature-dependent thermal physical properties and mechanical properties were considered to calculate the welding residual stress. The welding conditions and properties of steel were shown in Tables 1 and 2, respectively.

Welding-pass grouping sequence is shown in Figure 3. The full model has the same welding sequence of the real welding specimen. The full grouping model has a welding sequence of welding-pass grouping in the full model. The welding passes in the same layer merge into one pass in the full grouping model. The half model is the half portion of a full grouping model to reduce the analysis time. Through this analysis, the effect of welding-pass grouping and half model was investigated.

Figure 4 shows the two-dimensional model of $70 \mathrm{~mm}$ thickness. In order to investigate the effect of welding-pass grouping, welding-pass models were formed and organized into 4 categories as shown in Figure 5. Figure 5(a) is the same model of real welding passes (60 passes); (b) shows the model 


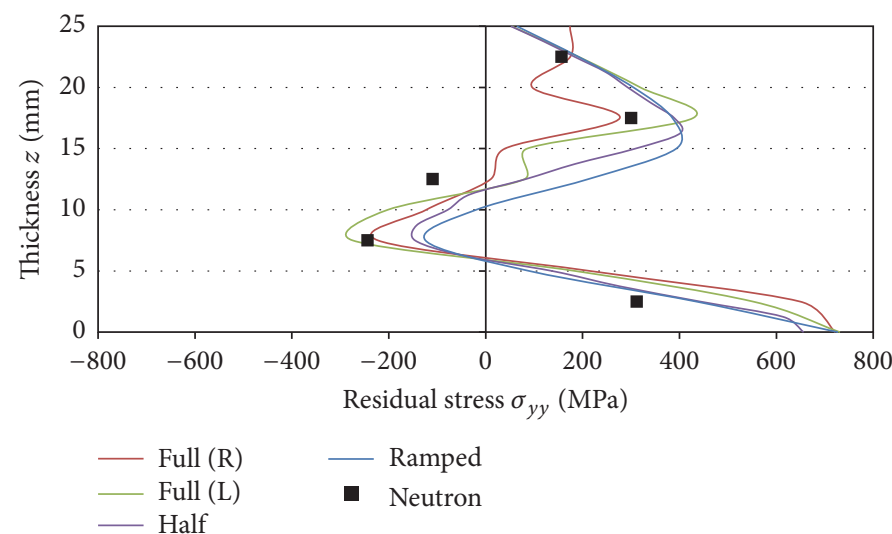

(a)

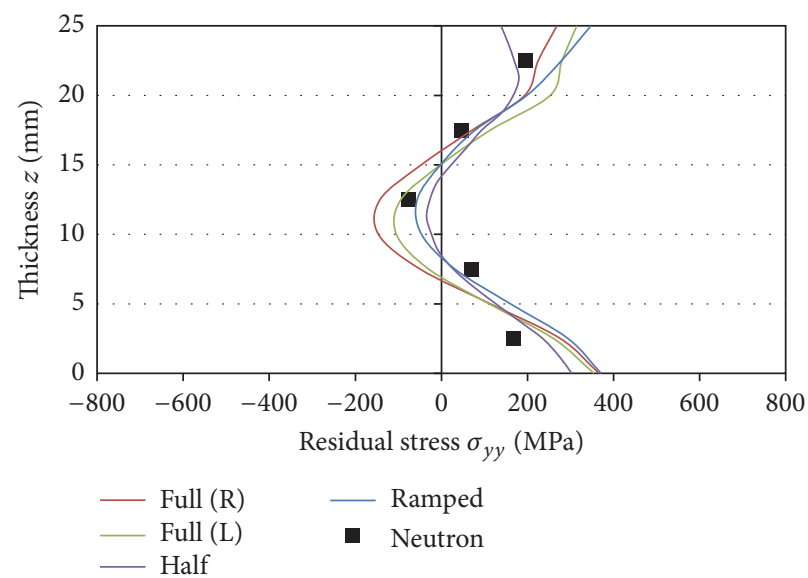

(c)

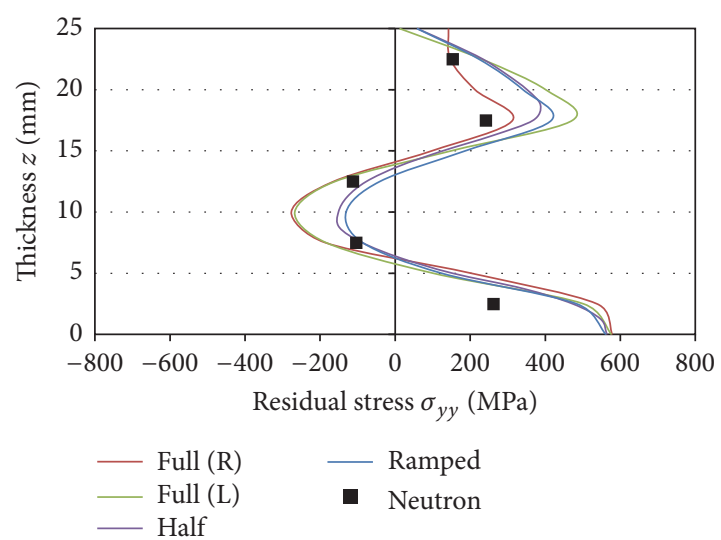

(b)

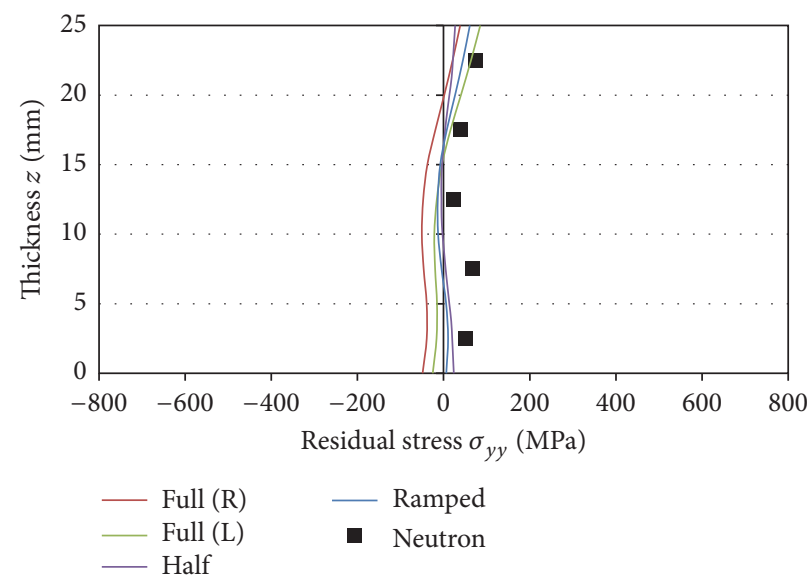

(d)

FIGURE 12: Welding residual stress in width direction, thickness $=25 \mathrm{~mm}$ at (a) $y=5 \mathrm{~mm}$, (b) $y=12.5 \mathrm{~mm}$, (c) $y=20 \mathrm{~mm}$, and (d) $y=35 \mathrm{~mm}$.

of a half pass of real welding passes; (c) is model of grouping the real welding pass to 8 layers and 8 passes; (d) is the model of grouping the real welding pass to 4 layers and 4 passes.

As the weldment thickness increases, the number of weld passes also increases, which need a lot of computation time to analyze the welding residual stress. A lumped pass model [3] was developed to reduce the total computational time. It assumes that a couple of weld beads merge into one lumped pass. As shown in Figure 6(a), the actual welding time for the heat source to pass through the unit thickness of the model is $t_{1}+t_{2}$. The term $t_{3}$ indicates the ramp-down time and is assumed to be the same as $t_{1}$. The heat flux magnitudes and heating duration in an accumulative manner are determined as Figures 6(b) and 6(c). The specification of the computer employed in this analysis is as follows: the CPU is an Intel Core $^{\mathrm{TM}} \mathrm{i7}-5775 \mathrm{C} 3.30 \mathrm{GHz}$ processor, the memory is $16 \mathrm{~GB}$, and the GPU is an NVIDIA GeForce GTX 960 processor having 1024 computing units. The ratio of computing time of each model is shown in Table 3. The computational time dramatically decreases with the reduction of layer and passes. This study verifies the effect of the welding-pass grouping on the computing time and the analysis results.
The welding residual stresses of thermal elastoplastic FE analysis in the welding direction of $25 \mathrm{~mm}$ thickness are shown in Figure 7: (a) is the result of the full model, (b) is the result of the full grouping model; (c) is the result of the half model. The residual stresses of 3 models in welding direction seem to be agreeing well. The tensile residual stress was generated in the vicinity of the weld joint while away from the welding joint where the compressive residual stress occurred. There are asymmetry residual stresses near final welding pass due to the welding sequence in Figure 7(a). Maximum tensile residual stress occurred under final welding pass due to the restraint of previous welding metal.

Welding residual stresses of thermal elastoplastic FE analysis in the welding and width direction of $70 \mathrm{~mm}$ thickness are shown in Figure 8: (a) is the result of 60 welding passes, (b) is the result of 30 welding passes; (c) is the result of 8 layers- 8 passes; (d) is the result of 4 layers- 4 passes. The distributions of the approximate residual stress are highly similar to each other. Welding residual stress is all tensile in the welding direction but on the other hand, residual stress in the width direction of the compressive residual stress was generated in the internal portion and the tensile part in both surfaces. 


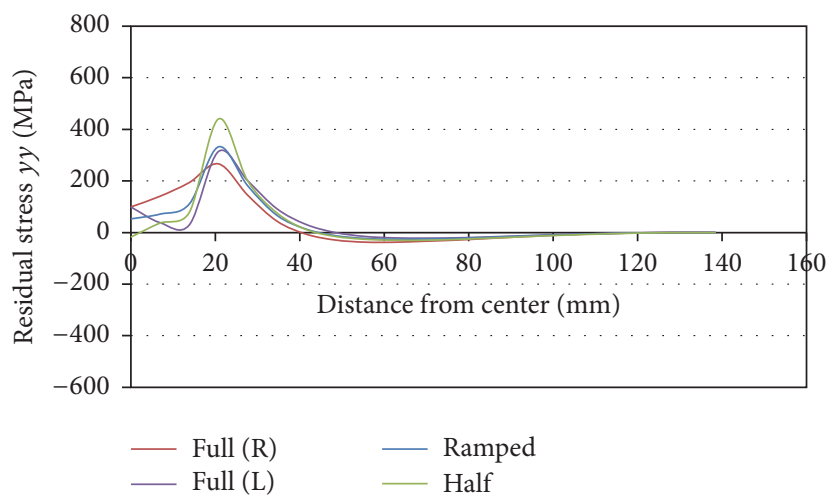

(a) At line top, $z=25 \mathrm{~mm}$

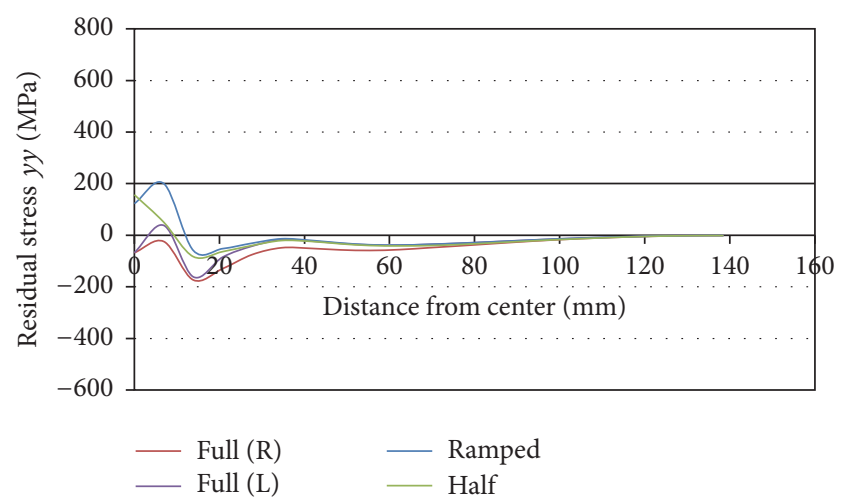

(b) At line middle, $z=12.5 \mathrm{~mm}$

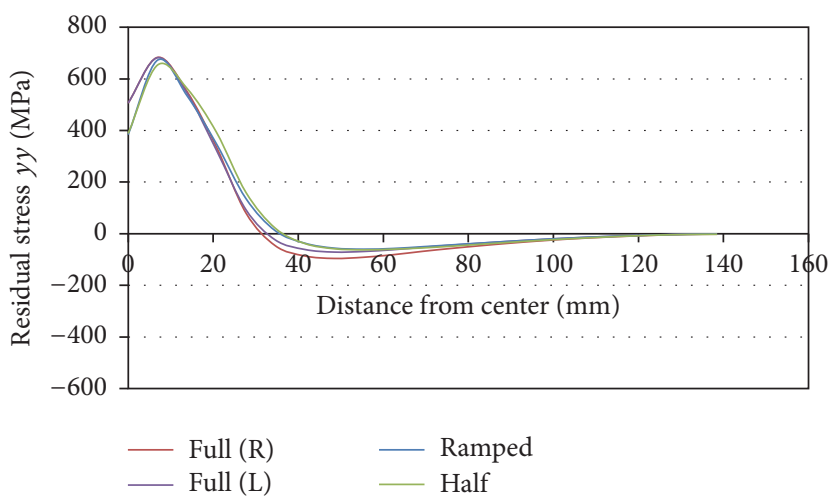

(c) At line bottom, $z=0 \mathrm{~mm}$

FIGURE 13: Welding residual stress in width direction, thickness $=25 \mathrm{~mm}$ at line top (a), middle (b), and bottom (c).

TABLE 3: Computation time according to each model.

\begin{tabular}{|c|c|c|c|c|}
\hline Thickness (mm) & Model & Layer & Pass & Ratio of computation time (\%) \\
\hline \multirow{3}{*}{25} & Full & 9 & 13 & 100 \\
\hline & Ramped & 9 & 9 & 73 \\
\hline & Half & 7 & 7 & 9 \\
\hline \multirow{4}{*}{70} & 2D_60 & 21 & 60 & 100 \\
\hline & 2D_30 & 21 & 30 & 59 \\
\hline & 2D_8 & 8 & 8 & 22 \\
\hline & 2D_4 & 4 & 4 & 8 \\
\hline
\end{tabular}

\section{Results of Analysis and Experiment and Discussions}

Figure 9 shows the coordinate and position for comparing the welding residual stresses of thermal elastoplastic FE analysis. Figure 10 shows the internal residual stress of welding direction according to positions $y=5,12.5,20$, and $35 \mathrm{~mm}$ from the center of the welding joint in a specimen thickness of $25 \mathrm{~mm}$. Figure 10 shows the residual stress according to top, middle, and bottom of thickness in the welding direction. The left/right stresses around the weld center were shown separately in order to examine the difference by the welding sequence. The results of neutron diffraction method were compared with those of thermal elastoplastic FE analysis. The results of the half and full grouping model are between the left/right results of the full model. The results of neutron agree with the right result of thermal elastoplastic FE analysis at $y=12.5 \mathrm{~mm}$. There are differences between the results of the experiment and analysis which are over $20 \mathrm{~mm}$ from the weld joint because the area is affected by the initial stress [3] and the residual stress (Figure 11) is fluctuating near $y=20 \mathrm{~mm}$. Initial stress, which is generated during the manufacturing of steel structure, occurs due to a temperature difference on the surface and inner side of steel while it goes through the heating and cooling process during manufacturing. According to research results, the magnitude of initial stress during steel manufacturing occurred until almost $60 \%$ of yield stress [3]. Figure 11 shows the residual stress according to top, middle, and bottom of thickness in welding direction. There was no big difference of welding 

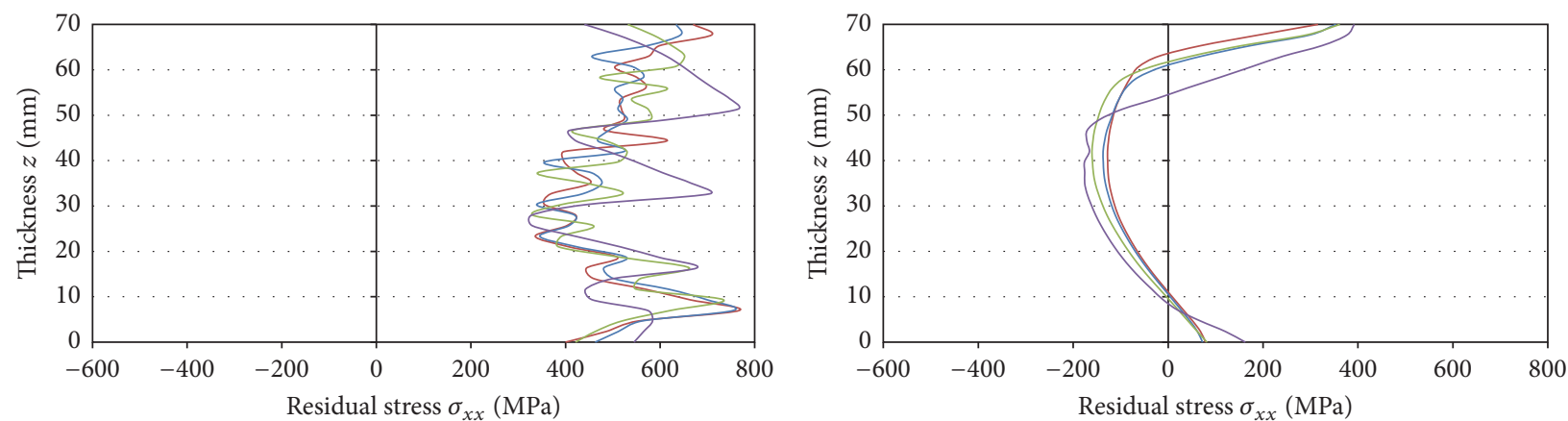

-60 passes $\quad 8$ passes
-30 passes

(a)

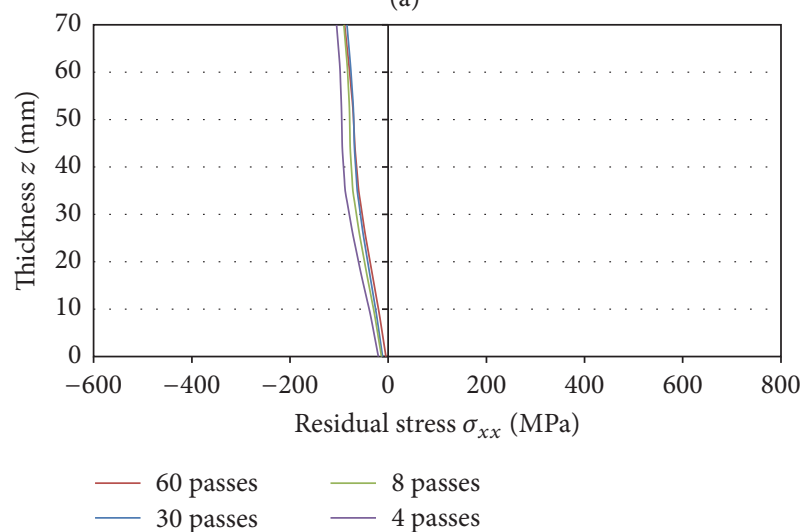

- 60 passes $\quad 8$ passes

- 30 passes $\quad 4$ passes

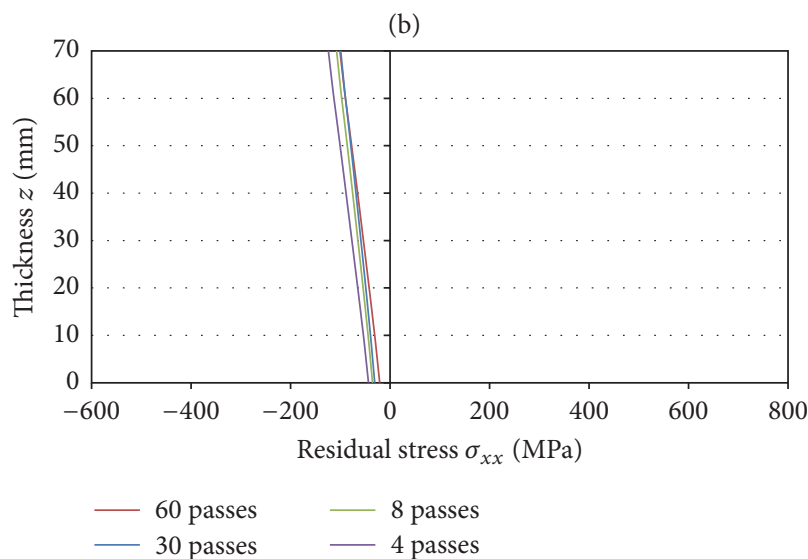

(c)

(d)

FIGURE 14: Welding residual stress in welding direction, thickness $=70 \mathrm{~mm}$ at (a) $y=5 \mathrm{~mm}$, (b) $y=30 \mathrm{~mm}$, (c) $y=60 \mathrm{~mm}$, and (d) $y=100 \mathrm{~mm}$.

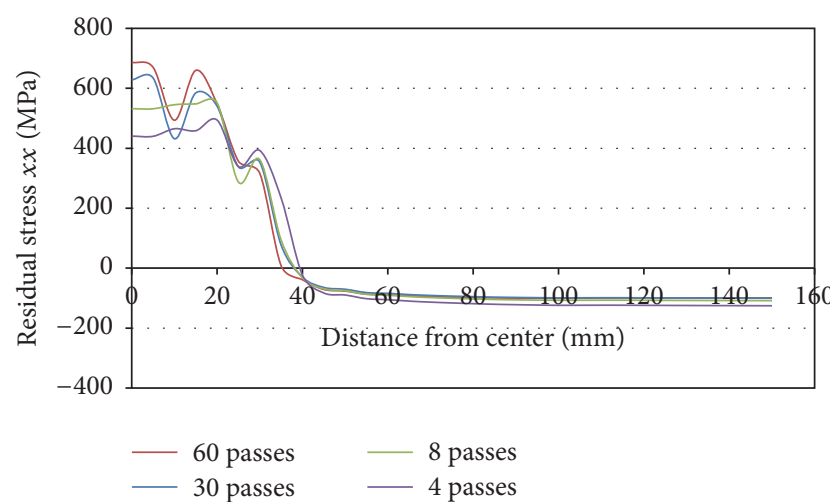

(a) At line top, $z=70 \mathrm{~mm}$

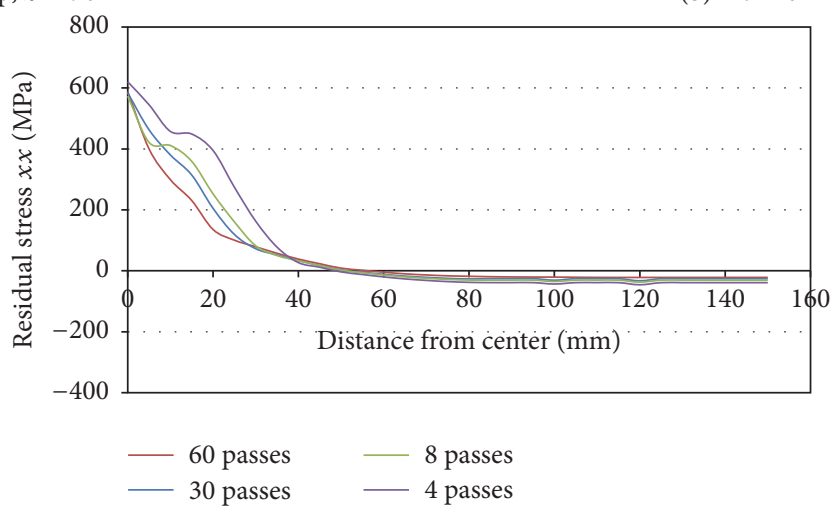

(c) At line bottom, $z=0 \mathrm{~mm}$ 


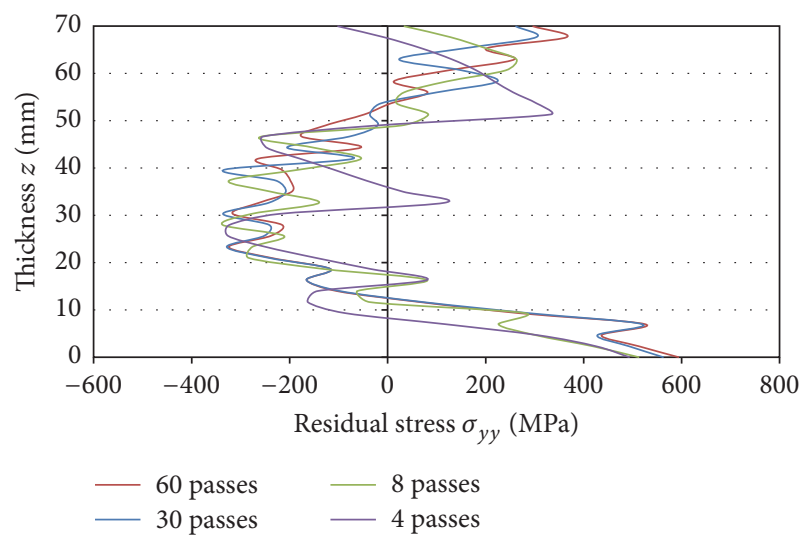

(a)

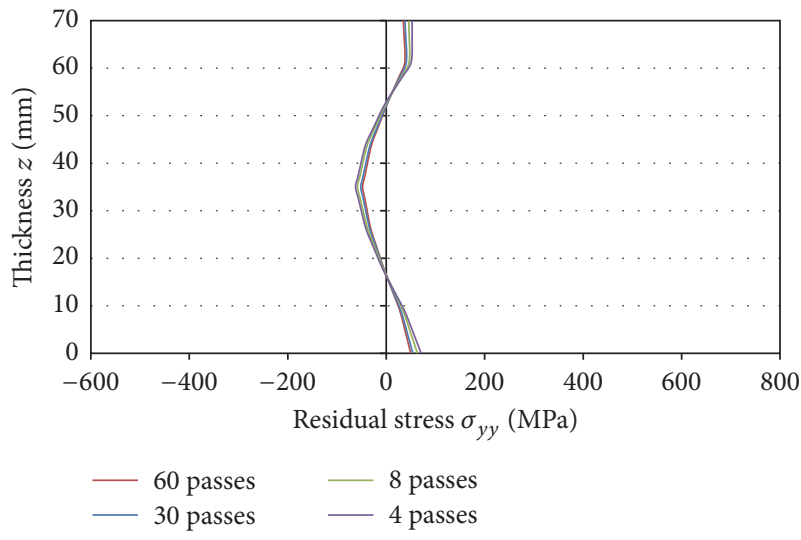

(c)

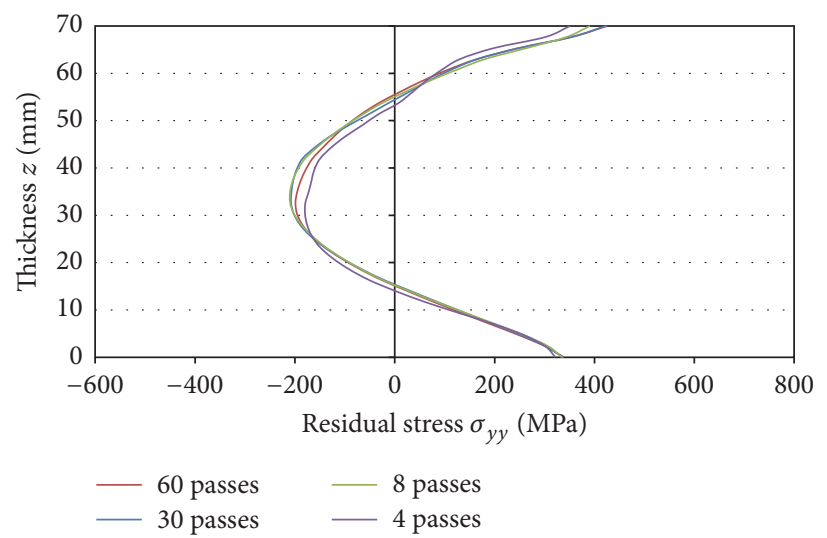

(b)

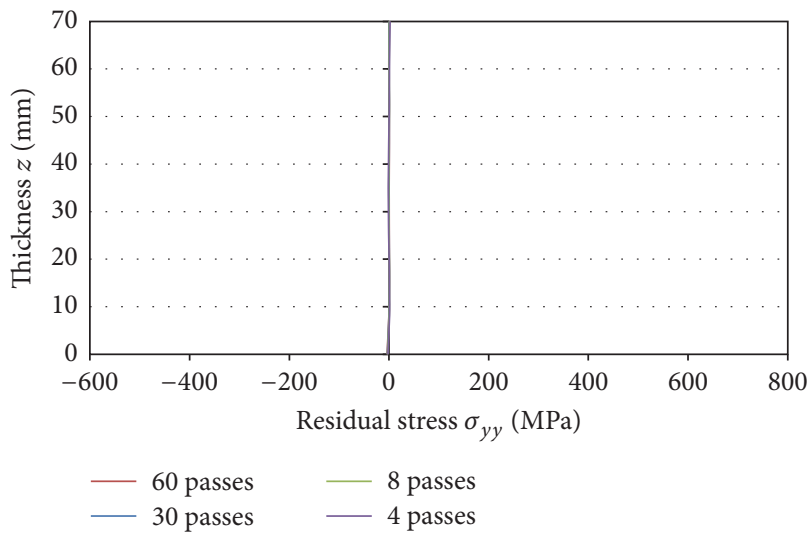

(d)

FIGURE 16: Welding residual stress in width direction, thickness $=70 \mathrm{~mm}$ at (a) $y=5 \mathrm{~mm}$, (b) $y=30 \mathrm{~mm}$, (c) $y=60 \mathrm{~mm}$, and (d) $y=$ $100 \mathrm{~mm}$.

residual stress according to the analytical model in width direction.

Figure 12 shows the internal residual stress of width direction according to positions $y=5,12.5,20$, and $35 \mathrm{~mm}$ from the center of welding joint in $25 \mathrm{~mm}$ thick specimen. Figure 13 shows the residual stress according to top, middle, and bottom of thickness in width direction. The tensile residual stress occurred in both surface and compressive residual stress in the inner side at $y=5 \mathrm{~mm}$. The maximum tensile residual stress was generated near the first welding pass. Such a large tensile stress can adversely affect the safety of the structure in combination with the stress increase due to the weld bead shape. Both the results of experiment and analysis agreed well and there were no differences according to the analysis model.

Figure 14 shows the internal residual stress of the welding direction according to positions $y=5,30,60$, and $100 \mathrm{~mm}$ from the center of the welding joint in $70 \mathrm{~mm}$ thick specimen. Figure 15 shows the residual stress according to top, middle, and bottom of thickness in welding direction. There are big differences in residual stress according to the welding-pass grouping method at $y=5 \mathrm{~mm}$ from welding center in welding direction. A difference of about $300 \mathrm{MPa}$ occurred in the analysis when less than half of the total number of weld passes is grouped in the weld pass. However, if the total number of welding passes grouping not exceeds the half of the total number of the real welding passes, the residual stress of welding-pass grouping model is similar to that of the real welding-pass model.

Figure 16 shows the internal residual stress of width direction according to positions $y=5,30,60$, and $100 \mathrm{~mm}$ from the center of welding joint in $70 \mathrm{~mm}$ thick specimen. Figure 17 shows the residual stress according to top, middle, and bottom of thickness in width direction. The residual stresses of width direction are affected by welding-pass grouping like in welding direction. In particular, there is a difference of $400 \mathrm{MPa}$ to reduce the real welding pass to 4 welding passes and the range affected by grouping is near the weld metal. This result is very similar to that of Shibahara' research which simulated the pipe structure which has an $\mathrm{X}$-shaped groove with 23 layers and 108 welding passes. In order to reduce analysis time and memory, a total number of 23 layers were reduced by 6 layers (26\%). The welding residual stress of the full model and grouping model has a lot of differences in terms of distribution shape and magnitude of the residual stress [22].

From the results above, it can be drawn that the weldingpass grouping affects the residual stress on the left/right side 


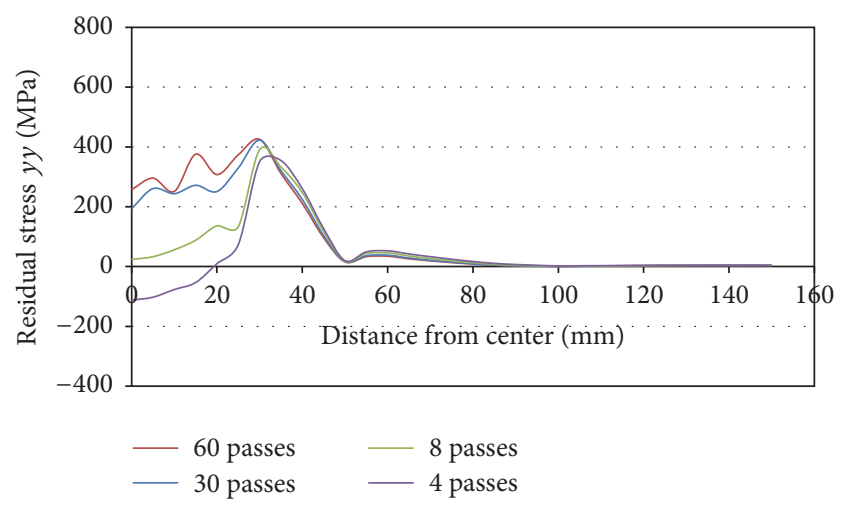

(a) At line top, $z=70 \mathrm{~mm}$

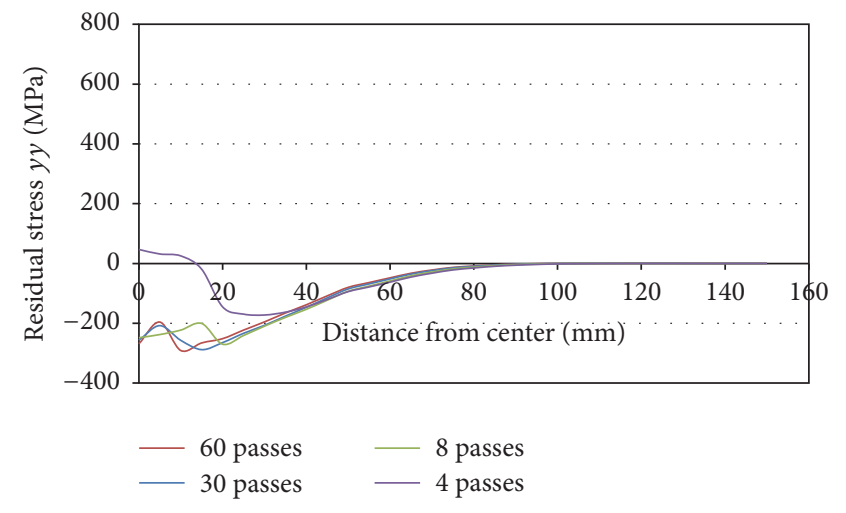

(b) At line middle, $z=35 \mathrm{~mm}$

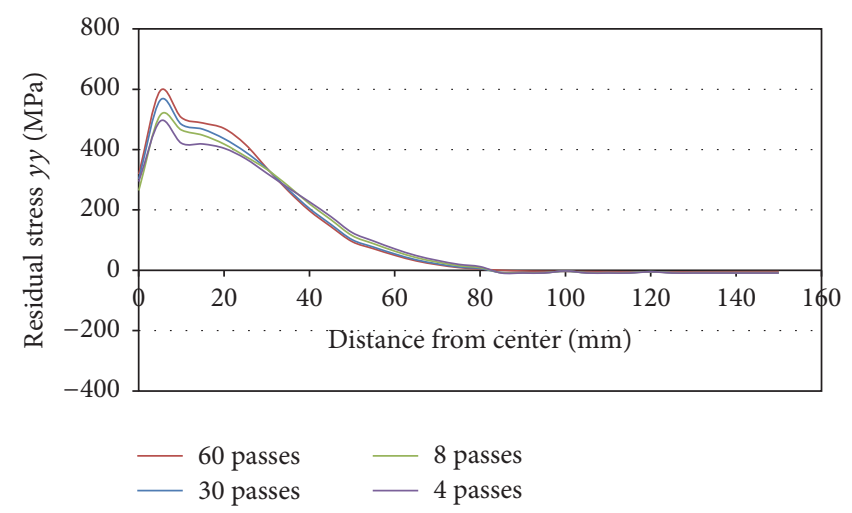

(c) At line bottom, $z=0 \mathrm{~mm}$

FIGURE 17: Welding residual stress in width direction, thickness $=70 \mathrm{~mm}$ at line top (a), middle (b), and bottom (c).

value and near the weld metal if welding pass is reduced for over half of the real welding passes number. Increasing the thickness of welding joint, the residual stress of width direction is affected by welding-pass grouping.

\section{Conclusion}

This study investigated the effect of residual stress due to welding-pass grouping as a way to reduce the analysis time in multipass thick butt welding joint. For this purpose, the parametric analysis which changes the number of grouping passes was conducted in a multipass butt weld with thicknesses of $25 \mathrm{~mm}$ and $70 \mathrm{~mm}$. In addition, the residual stress by thermal elastoplastic FE analysis was compared with the results by the neutron diffraction method for verifying the reliability of the $\mathrm{FE}$ analysis. The summary is as follows.

(1) The welding sequence is considered in order to predict more accuracy in the residual stress when using welding-pass grouping. The residual stress of the welding-pass grouping model and half model occurred between the results of the left/right welding pass of full model.

(2) The residual stresses of the half model using $1 / 2$ of full model agreed with one of the left/right of the full model.
(3) The residual stress measurements by neutron method were in good agreement with the full model results. Therefore, the reliability of the thermal elastoplastic FE analysis result was confirmed.

(4) Upon increasing the thickness of welding joint, the residual stress in width direction is affected by welding-pass grouping more than in welding direction and the area affected by welding-pass grouping is just near the welding joint.

\section{Competing Interests}

The authors declare that they have no conflict of interests regarding the publication of this paper.

\section{Acknowledgments}

This study was supported by research fund from Chosun University, 2016.

\section{References}

[1] G. B. An, "Increase of brittle crack arrestability using arrest welding with thick steel plate in large container ship," in Proceedings of the 21st International Offshore and Polar Engineering Conference, Maui, Hawaii, USA, June 2011. 
[2] G. B. An, W. Woo, and J.-U. Park, "Brittle crack-arrest fracture toughness in a high heat-input thick steel weld," International Journal of Fracture, vol. 185, no. 1-2, pp. 179-185, 2014.

[3] J.-U. Park, G. An, W. C. Woo, J.-H. Choi, and N. Ma, "Residual stress measurement in an extra thick multi-pass weld using initial stress integrated inherent strain method," Marine Structures, vol. 39, pp. 424-437, 2014.

[4] J.-U. Park, W. C. Woo, G. An, and N. Ma, "Comparison of measured residual stress distributions in extra-thick butt welds joined by one-pass EGW and multipass FCAW," Advances in Mechanical Engineering, vol. 2014, Article ID 861247, 11 pages, 2014.

[5] M. Birkholz, C. Genzel, and T. Jung, "X-ray diffraction study on residual stress and preferred orientation in thin titanium films subjected to a high ion flux during deposition," Journal of Applied Physics, vol. 96, no. 12, pp. 7202-7211, 2004.

[6] O. Sicot, X. L. Gong, A. Cherouat, and J. Lu, "Influence of experimental parameters on determination of residual stress using the incremental hole-drilling method," Composites Science and Technology, vol. 64, no. 2, pp. 171-180, 2004.

[7] S. Okido, M. Hayashi, K. Tanaka, Y. Akinawa, N. Minakawa, and Y. Mori, "Measurement of residual stress in textured $\mathrm{Al}$ alloy by neutron diffraction method," in Proceedings of the 7th International Conference on Nuclear Engineering (ICONE '99), pp. 19-23, Tokyo, Japan, April 1999.

[8] W. Woo, G. B. An, E. J. Kingston, A. T. De Wald, D. J. Smith, and M. R. Hill, "Through-thickness distributions of residual stresses in two extreme heat-input thick welds: a neutron diffraction, contour method and deep hole drilling study," Acta Materialia, vol. 61, no. 10, pp. 3564-3574, 2013.

[9] D. J. Smith, P. J. Bouchard, and D. George, "Measurement and prediction of residual stresses in thick-section steel welds," Journal of Strain Analysis for Engineering Design, vol. 35, no. 4, pp. 287-305, 2000.

[10] A. H. Mahmoudi, S. Hossain, C. E. Truman, D. J. Smith, and M. J. Pavier, "A new procedure to measure near yield residual stresses using the deep hole drilling technique," Experimental Mechanics, vol. 49, no. 4, pp. 595-604, 2009.

[11] H. Murakawa, Y. Luo, and Y. Ueda, "Prediction of welding deformation and residual stress by elastic FEM based on inherent strain (first report) mechanism of inherent strain production," Journal of the Society of Naval Architects of Japan, vol. 180, pp. 739-751, 1996.

[12] M. B. Prime, "Cross-sectional mapping of residual stresses by measuring the surface contour after a cut," Journal of Engineering Materials and Technology, Transactions of the ASME, vol.123, no. 2, pp. 162-168, 2001.

[13] Y. Ha, "A study on weldment boundary condition for elastoplastic thermal distortion analysis of large welded structures," Journal of Welding and Joining, vol. 29, no. 4, pp. 48-53, 2011.

[14] Y. Ha and J. Yang, "Development of distortion analysis method for multi-pass butt-welding based on shell element," Journal of the Korean Welding and Joining Society, vol. 28, no. 1, pp. 54-59, 2010.

[15] K. Ikushima, A study of development of prediction method of welding deformation and stresses of welded structures using idealized explicit FEM [Ph.D. thesis], Osaka Prefecture University, 2014.

[16] N. Ma, "An accelerated explicit method with a two-stage computation scheme for transient thermal stress and welding deformation," Transactions of JWRI, vol. 44, no. 1, pp. 31-40, 2015.
[17] M. Shibahara and K. Ikushima, "Development of analytical method for welding mechanics using idealized explicit FEM," Transactions of JWRI, vol. 39, no. 2, pp. 384-386, 2010.

[18] N. Ma, "An accelerated explicit method with GPU parallel computing for thermal stress and welding deformation of large structure models," International Journal of Advanced Manufacturing Technology, vol. 87, no. 5, pp. 2195-2211, 2016.

[19] N. Ma and S. Yuan, "An accelerated explicit method and GPU parallel computing for thermal stress and welding deformation of automotive parts," International Journal of Applied Mechanics, vol. 8, no. 2, Article ID 1650023, 23 pages, 2016.

[20] J. K. Hong, C.-L. Tsai, and P. Dong, "Assessment of numerical procedures for residual stress analysis of multipass welds," Welding Journal, vol. 77, no. 9, pp. 372-382, 1998.

[21] Y. Shim, Z. Feng, S. Lee et al., "Determination of residual stresses in thick-section weldments," Welding Journal, vol. 71, no. 9, pp. 305-312, 1992.

[22] K. Ikushima and M. Shibahara, "Large-scale non-linear analysis of residual stresses in multi-pass pipe welds by idealized explicit FEM," Welding in the World, vol. 59, no. 6, pp. 839-850, 2015. 


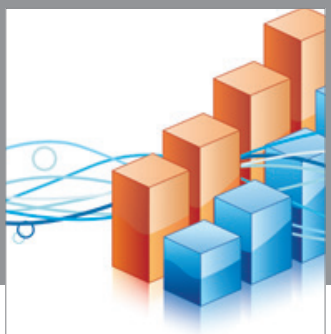

Advances in

Operations Research

vatem alat4

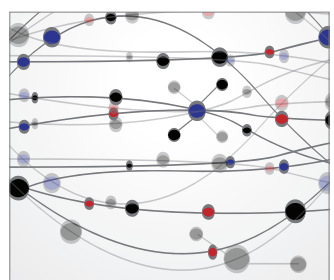

\section{The Scientific} World Journal
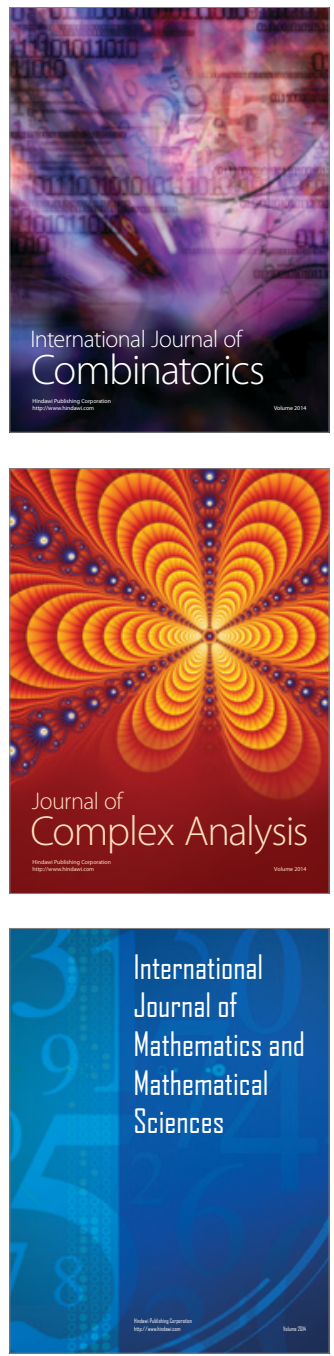
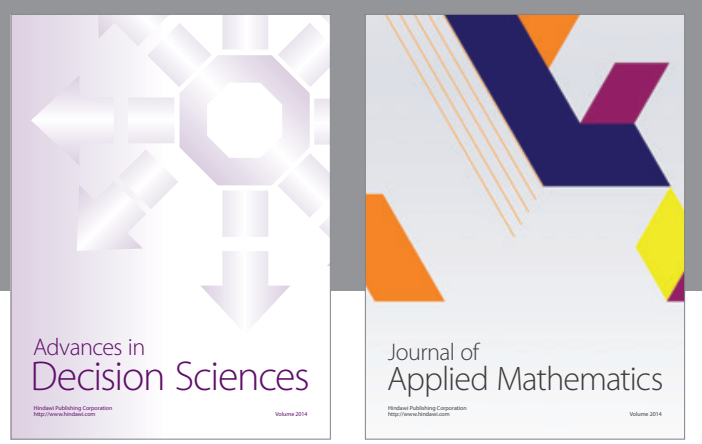

Algebra

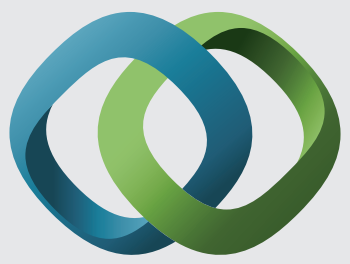

\section{Hindawi}

Submit your manuscripts at

https://www.hindawi.com
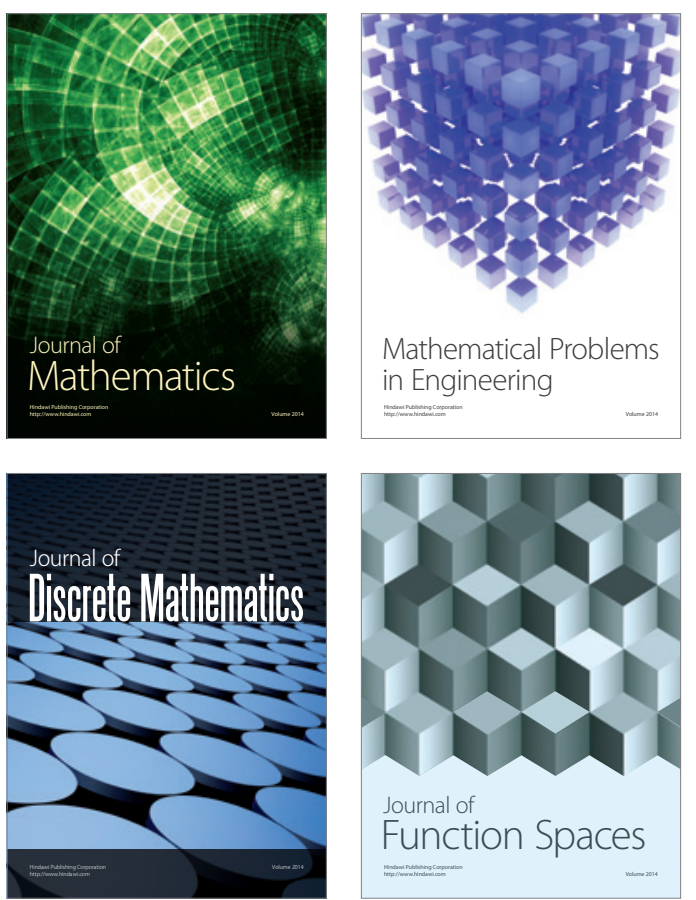

Mathematical Problems in Engineering
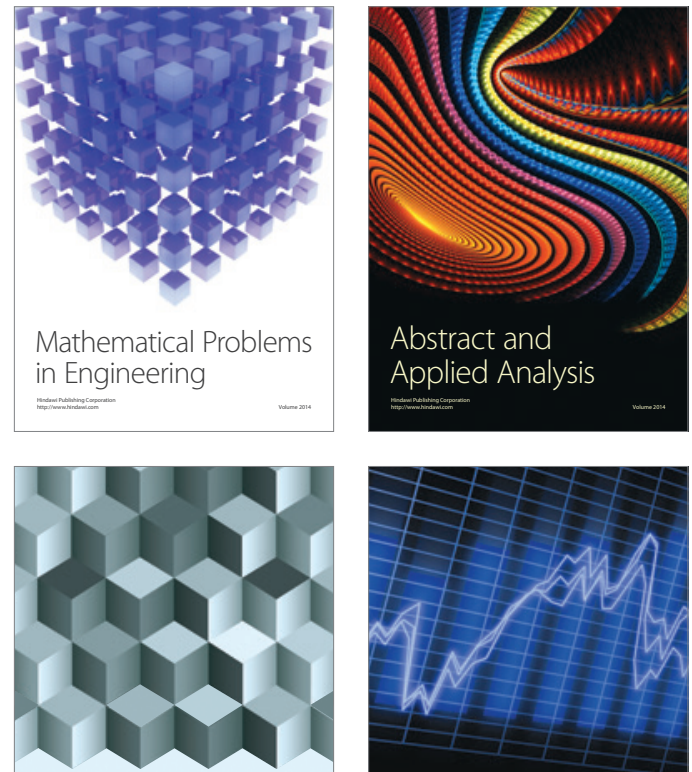

Journal of

Function Spaces

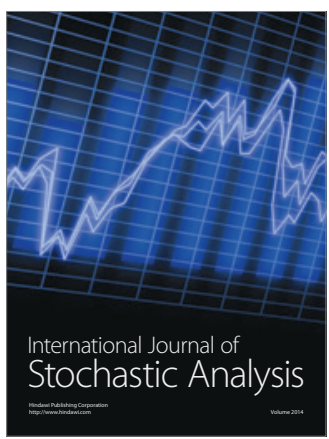

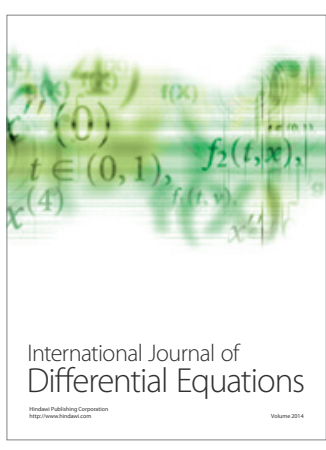
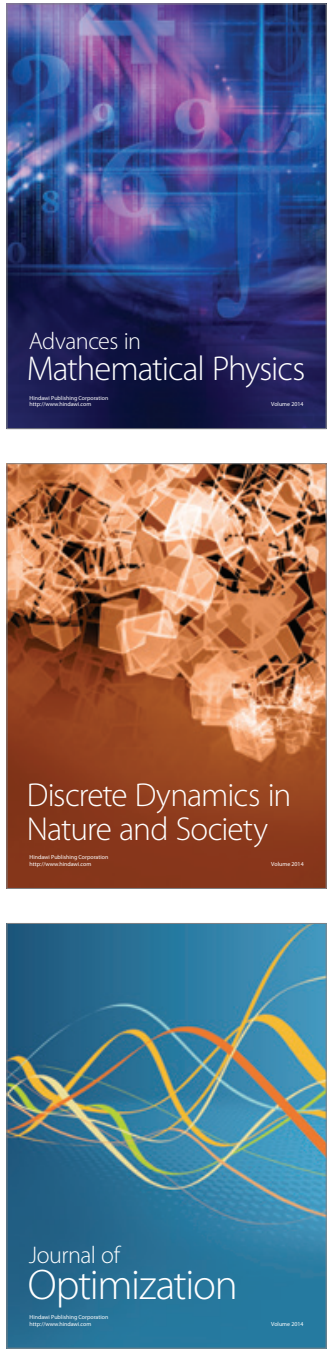